\title{
Gêneros textuais e livros didáticos: um estudo de caso na educação a distância $(\mathrm{EaD})$
}

\author{
Textual genders and teaching books: a case study on distance education
}

$(\mathrm{DE})^{1}$

Jorge França de Farias Jr

Mestre e Doutor em Linguística/Universidade Estadual de Campinas

Pós-Doutor em Linguística e Antropologia Social/University College London

Professor e Pesquisador Associado/Universidade Federal Rural de Pernambuco

jorge_jr_99@yahoo.com

Resumo: Este artigo apresenta o interesse em se analisar a predominância do gênero textual multimodal por meio do material didático impresso produzido para cursos de Letras e Pedagogia em Educação a Distância (EAD), especificamente para disciplinas de Língua Portuguesa. Como parte de um projeto de Iniciação Científica, esta pesquisa teve como objetivo geral fazer com que os alunos/pesquisados produzissem material instrucional didático. Especificamente, o objetivo foi de que os alunos inserissem gêneros textuais multimodais nos materiais a serem produzidos. Para tanto, houve a necessidade de se seguir a seguinte metodologia: 1) analisar o uso dos gêneros textuais multimodais nos livros didáticos e 2) fazer um levantamento de suas ocorrências e das diferenças de suas aplicações para os livros didáticos de cada curso. Aqui, neste artigo, me aterei apenas a esta primeira etapa do projeto que é de cunho metodológico, a saber, o de recortar e de analisar trechos de livros didáticos. Chegou-se à conclusão, com esta pesquisa, que nos materiais didáticos de Letras há mais enfoque para questões de gêneros textuais, enquanto os livros didáticos de Pedagogia voltam-se mais a questões de interpretação textual.

Palavras-chave: Educação a distância. Gêneros textuais. Língua portuguesa. Material didático.

Abstract: This article presents the interest in analyzing the predominance of the multimodal textual genre through the printed didactic material produced for courses of Letters and Pedagogy in Distance Education (EAD), specifically for Portuguese language subjects. As part of a Scientific Initiation project, this research had the general objective of making students / respondents produce educational instructional material. Specifically, the objective was for students to insert multimodal textual genres in the materials to be produced. Therefore, there was a need to follow the following methodology: 1) analyze the use of multimodal textual genres in textbooks and 2) make a survey of their occurrences and the differences in their applications for the textbooks of each course. Here, in this article, I will stick only to this first stage of the project, which is of a methodological nature, namely, to cut and analyze excerpts from textbooks. It was concluded, with this research, that in the didactic materials of Literature there is more focus on issues of textual genres, while the textbooks of Pedagogy focus more on questions of textual interpretation.

Keywords: Distance education. Textual genres. Portuguese language. Didactic material. 


\section{Introdução}

A produção de material didático impresso para Educação a Distância (EaD) tem sido objeto de estudo de muitos pesquisadores, os quais consideram como características essenciais para esse tipo de material, entre outras: o dialogismo na linguagem, a presença da iconicidade e a proposição de atividades diversificadas, elementos esses atenuantes da distância física entre professor e aluno. Percebe-se, assim, que a aprendizagem nessa modalidade educacional depende, em grande parte, da forma como os textos se apresentam aos alunos, ou seja, da utilização adequada dos gêneros textuais empregados.

A partir desta perspectiva, buscou-se analisar a utilização de gêneros textuais em livros didáticos para Educação a Distância $(\mathrm{EaD})$, especificamente os voltados aos cursos de Pedagogia e Letras de universidades vinculadas ao Programa Universidade Aberta do Brasil (UAB). Foram analisados tais materiais didáticos, tendo em vista aspectos estruturais e linguísticos interligados à questão dos gêneros textuais. Para tanto, adotou-se os seguintes procedimentos:

1) leitura e fichamento de textos teóricos acerca da abordagem de gêneros textuais e da produção de material didático impresso para EaD;

2) levantamento do corpus;

3) produção de roteiro de análise; e

4) análise do material coletado.

Como fundamentação teórica foram utilizadas as considerações acerca de gêneros textuais de Marcuschi (2002) e (2008) e Bakhtin (1997) e, sobre material didático impresso para EaD, de Preti (2010) e Silva (2010).

Metodologicamente, o projeto seguiu os seguintes passos:

i) coletar os dados para a implementação da proposta através de textos disponibilizados na Internet e/ou por meio de pesquisa de campo em comunidades virtuais (fóruns, batepapos, propostas de atividades sugeridas pelos professores/tutores);

ii) recortar e quantificar os dados coletados a fim de, posteriormente, serem transcritos e digitalizados pelos alunos nas aulas laboratoriais; e

iii) produzir o material didático que será disponibilizado para o curso de letras, nas universidades públicas, como material de apoio para aulas de língua portuguesa. 
A pesquisa contemplou a análise de quatro livros didáticos, sendo dois do curso de Licenciatura em Pedagogia e dois de Licenciatura em Letras, adotando-se, respectivamente, materiais das disciplinas Literatura Infantil/Infanto-juvenil e Produção Textual. Como veremos detalhadamente nas análises, observou-se disparidades em relação à abordagem de gêneros entre os dois cursos.

Após leituras de fundamentação teórica e exame preliminar dos materiais selecionados, fezse um roteiro de análise (anexo) composto por 10 questões com alternativas objetivas sobre a abordagem de gêneros textuais no livro didático, a saber:

1. O livro didático apresenta diversidade de gêneros textuais?

2. De que forma a diversidade de gêneros é apresentada?

3. Os gêneros abordados vinculam-se à proposta curricular destinada?

4. As atividades favorecem a aprendizagem de habilidades quanto aos gêneros abordados e facilitam a aplicação de conhecimentos no âmbito profissional, social, familiar, etc.?

5. Quais são os gêneros selecionados pelo autor do livro didático?

6. Com que recorrência os gêneros selecionados apresentam-se no livro?

7. Os gêneros apresentados estabelecem conexões entre si? (Por exemplo, são de um mesmo domínio discursivo?)

8. Os gêneros abordados apresentam reflexão acerca da intertextualidade e/ou intergenericidade textual?

9. Há no material atividades que auxiliem o aluno quanto à leitura e produção de gêneros acadêmicos?

10. Há abordagem de gêneros multimodais no material didáticos?

A pesquisa seguiu o roteiro de análise acima citado contemplando a observação de quatro livros didáticos, sendo dois do curso de Pedagogia e dois de Letras, respectivamente das disciplinas Literatura Infantil/Infanto-Juvenil e Produção Textual, elencados abaixo.

- GEHRKE, N. A. EAD 1108 - Produção Textual. (Desenvolvimento de material didático ou instrucional - Disciplina EAD), 2009.

- SACRAMENTO, S. M. P. do; RODRIGUES, I. de O. Pedagogia - Literatura Infanto-juvenil. Módulo 5, Volume 1, EAD. Ilhéus: Edictus, 2011.

- SILVEIRA, M. C., A. de A. Literatura Infantil. In: BRENNAND, Edna Gusmão de Góes; ROSSI, Silvio José; BEZERRA, Lebiam Tamar Silva. Trilhas do Aprendente. João Pessoa: Editora Universitária da UFPB, 2008. V. 6. p.19- 46. 
- ZANDOMENEgO, D. CERUTTI-RIZZATTI, M. E. Produção Textual Acadêmica $I$ - $1^{\circ}$ período. - Florianópolis: LLV/CCE/UFSC, 2008.

\section{Entendendo o percurso dos gêneros textuais na EaD}

Na cultura ocidental, a linguagem verbal, seja ela escrita ou oral, tem sido considerada o modo dominante de comunicação ao longo dos tempos, sendo atribuída à escrita maior importância se a compararmos com outras modalidades como, por exemplo, a fala e os outros modos visuais, a saber: ilustrações, fotos, grafites etc., considerados apenas como "suportes ilustrativos da coisa real" (KRESS, 1993, p.03). Com a introdução da televisão nos meios de comunicação, com a ampla e massiva utilização de imagens em jornais, revistas, Internet, propaganda etc., a tese de prevalência da linguagem verbal tornou-se um pouco menos relevante e, cada vez mais, há uma necessidade de se considerar o texto no conjunto dos recursos multimodais que o compõem. Consequentemente, a partir da grande quantidade de informação que as pessoas recebem, por meio das mudanças tecnológicas, tem havido, nos dias atuais, um aumento do interesse pela linguagem não-verbal, quando temos que ler um texto, qualquer que seja, principalmente, os textos expostos pela mídia, de um modo geral.

Não é mais possível ler um texto prestando-se atenção unicamente à mensagem escrita, pois esta representa apenas um elemento informacional que coexiste com uma série de outros, como a formatação, o tipo de fonte, a presença de imagens e todo tipo de informação advinda de quaisquer modos semióticos embutidos na cultura humana e que estão presentes no texto, como a comida, as roupas, a diversão, a arte, a música, a fotografia etc. Segundo Dionísio (2005, p.159), “imagem e palavra mantêm uma relação cada vez mais próxima, cada vez mais integrada". Com isso, os textos passam a ser percebidos como construtos multimodais, dos quais a escrita é apenas um dos modos de representação das mensagens (KRESS e VAN LEEUWEN, 1996, 2001; JEWITT e KRESS, 2003). Estes outros recursos, também, constituem meios de expressão do conteúdo do texto que podem ser verificados, imprescindivelmente, a partir da construção de sentido estabelecida pelos materiais didáticos voltados para a Educação a Distância (EaD).

A produção de material didático para $\mathrm{EaD}$ tem sido objeto de estudo de muitos pesquisadores, abrangendo não só as inovações tecnológicas como, também, os materiais impressos. Segundo Preti (2010), os impressos têm seu espaço garantido nessa modalidade de ensino e aprendizagem em função de ser uma tecnologia mais acessível e a mais bem dominada, em virtude da sua intensa produção ainda existente. Isto indica que o uso do livro impresso está longe de se extinguir e se dá em razão da crescente procura das instituições por desenvolver materiais específicos para os cursos em EaD. Já no contexto da produção e da divulgação desse 
tipo de material, a diversificação de gêneros textuais que apresentem uma linguagem dialógica, aliada à presença da iconicidade, é uma característica essencial para que se atenue a distância física entre professor e aluno e para que a aprendizagem ocorra de maneira eficaz.

Em decorrência desta perspectiva que se faz necessária, quando trata da questão do ensino de línguas, especificamente de língua materna, os Parâmetros Curriculares Nacional-PCN's (BRASIL, 1998, p. 18) nos alerta para que o ensino de língua materna deve estar pautado nos gêneros discursivos, tanto orais como escritos. A partir disso, o estudo volta-se para a questão dos gêneros, principalmente para descrever a variedade existente. Por sua vez, Marcuschi (2002, p.19) ressalta que "os gêneros textuais são fenômenos históricos, profundamente vinculados à vida cultural e social”. Em outras palavras, podemos entender que uma das contribuições dos gêneros é ordenar e estabilizar as atividades comunicativas no âmbito sociocultural.

Para Bakhtin (1997, p.281-282), eles são instrumentos que fundam a possibilidade de comunicação. Bakhtin afirma que o sujeito se constitui à medida que ouve e assimila o discurso do outro. Para este autor, os gêneros do discurso são os padrões de construção composicional de um todo verbal e o estudioso os divide em gêneros primários e secundários. Os gêneros do discurso primários são aqueles usados no cotidiano, logo, são os mais simples. Já os gêneros do discurso secundários aparecem em comunicações sociais mais complexas como, por exemplo, em produções artísticas, científicas e na escrita. Este discurso bakhtiniano é encontrado nos PCNs de Língua Portuguesa (BRASIL, 1998, p. 18), que, sedimentados nessa teoria, propõem que o texto seja a unidade de ensino e os gêneros discursivos o objeto de ensino na sala de aula. Nesta perspectiva, o texto desenvolve o papel do agente integrador (unidade de significação) entre as práticas de leitura, análise linguística e produção de texto.

Seguindo a perspectiva de Marcuschi (2002, p. 31), a partir da qual os gêneros textuais constituem formas de realizar linguisticamente objetivos específicos em situações sociais particulares, e considerando que o objetivo maior da Educação é formar cidadãos competentes nas variadas situações sociais, interessa investigar de que maneira estão sendo trabalhados os diferentes gêneros textuais, visto que as práticas sociais humanas realizam-se por meio de textos, sejam eles verbais ou não-verbais, os quais materializam as mensagens a serem transmitidas e se ordenam por meio classificatório no enquadramento dentro de um gênero qualquer, em um dado contexto sociocultural, como bem esclarece Marcuschi (2008).

Atentar para essa abordagem implica analisar quais gêneros estão sendo utilizados, com que propósitos são inseridos no material, a forma como são trabalhadas as suas características de estrutura, conteúdo e estilo; as reflexões que são feitas em torno da sua funcionalidade, das relações 
intertextuais e intergenéricas; a abordagem prática em atividades contidas no material; os possíveis incentivos à produção de gêneros científicos, entre outros.

Conforme citado anteriormente, a avaliação dos materiais didáticos na $\mathrm{EaD}$ pautou-se no roteiro de análise produzido após leitura preliminar. Por uma questão de extensão, optou-se por apresentar os resultados e discussões cotejando-se os quatro livros por área (Letras e Pedagogia) e agrupando a análise em cinco tópicos principais: 1) Diversidade de gêneros e exploração teórica; 2) Atividades; 3) Produção textual acadêmica; e 4) Intertextualidade, intergenericidade e multimodalidade.

\title{
3 Abrindo o livro didático na EaD
}

No âmbito da produção de material didático impresso, deve-se levar em conta que o livro atua como o principal mediador entre o professor e o aluno. Portanto, é fundamental que se constitua por uma série de aspectos que atenuem a distância física entre esses agentes, como o emprego de ícones, da linguagem dialogal e do aprofundamento teórico que, articulados às orientações práticas, proporcionem ao graduando autonomia na aprendizagem.

Segundo Silva (2010, p. 319),

\begin{abstract}
É por meio dos materiais didáticos que as orientações de estudo são disponibilizadas aos alunos, bem como as informações sobre pesquisa, atividades propostas, dicas de estudo, planejamento de projetos, confecção de relatórios, ferramentas de interação online, enfim, uma multiplicidade de componentes pode estar integrada à produção de conteúdos pedagógicos com a finalidade de apoiar os educandos rumo à construção da autonomia.
\end{abstract}

Assim, segundo as considerações de Marcuschi (2002, p. 31) sobre a importância da familiaridade com os diversos gêneros textuais como veículo organizador das práticas sociais: "Quando dominamos um gênero textual, não dominamos uma forma linguística, e sim uma forma de realizar linguisticamente objetivos específicos em situaçoes sociais particulares". Importa investigar, portanto, como se apresenta tal mediação nesses materiais.

Nos quatro livros analisados, observou-se que a diversidade de gêneros se manifesta restrita a determinados domínios discursivos, fato que é justificado pela base temática de cada disciplina. Assim, nos dois livros de Pedagogia, cujas disciplinas são Literatura Infanto-juvenil e Literatura Infantil, são trabalhados uma variedade adequada de gêneros literário-ficcionais (fábula, parlenda, conto, poema, trava-línguas, histórias em quadrinhos, charge e cartum).

Já nos livros de Letras, observa-se a restrição ao domínio acadêmico, no caso do Produção Textual Acadêmica I (resumo, resenha, artigo, seminário/esquema/bandout, fichamento); e, no Produção Textual, a inserção de gêneros pertencentes a vários domínios (carta pessoal, carta aberta, 
carta ao leitor, ofício, memorando, e-mail). As seleções, encontram-se, portanto, condizentes com a ementas das respectivas disciplinas.

Quanto à abordagem dos gêneros selecionados nos livros de Pedagogia, percebeu-se, de maneira geral, que os autores poderiam trabalhá-los de maneira mais satisfatória. Focalizou-se mais a contextualização histórica da utilização dos gêneros selecionados, havendo, na maioria das vezes, apenas a inserção ilustrativa ou a limitação à interpretação textual. Esse aspecto, portanto, deixou a desejar no material com relação ao aprofundamento teórico quanto às características de estrutura, conteúdo e estilo e quanto à funcionalidade do gênero estudado.

Tal aspecto pode ser observado no exemplo abaixo, em que, ao tratar do gênero fábula, os autores dedicam apenas um parágrafo para trabalhar a parte teórica do gênero.

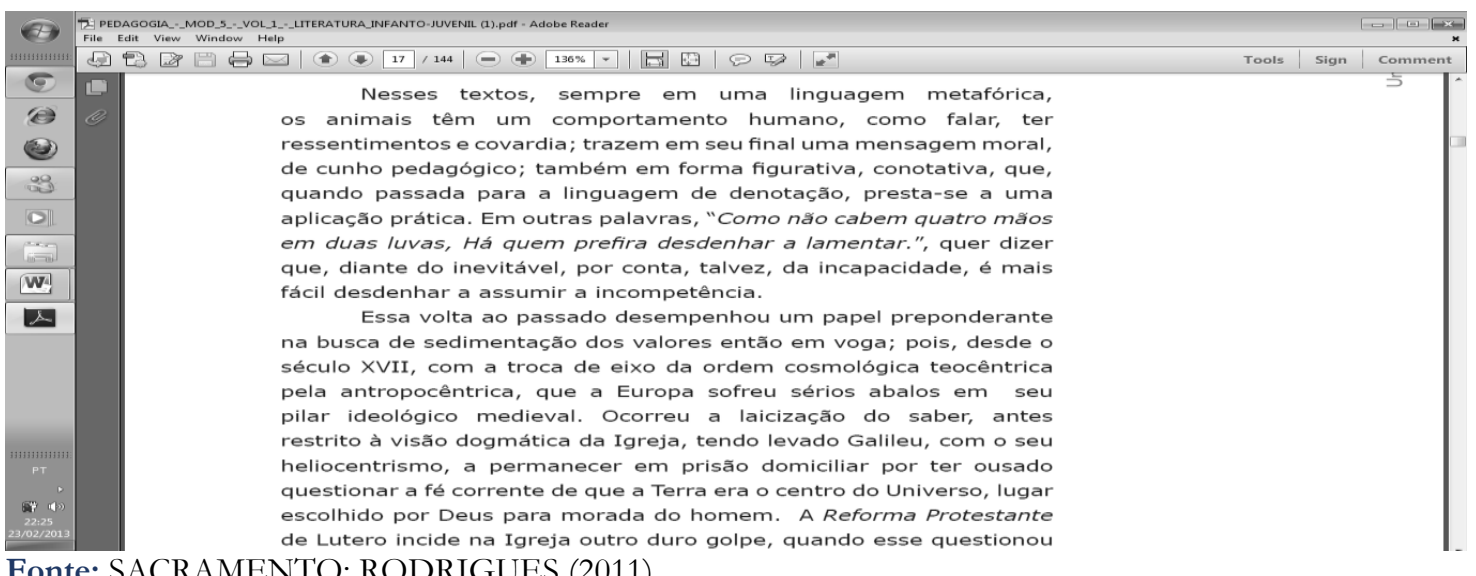

Fonte: SACRAMENTO; RODRIGUES (2011).

Em outros momentos dos materiais, ora o gênero é apenas citado, trazendo-se, no máximo, imagens de exemplares e explicações de obras pontuais - como é o caso da inserção do gênero história em quadrinhos, na discussão sobre reprodutibilidade técnica, no primeiro exemplo abaixo -, ora é feita apenas a descrição de determinadas obras, utilizando-se passagens da mesma, como no segundo exemplo. Nesse caso, percebeu-se uma maior preocupação em resenhar a obra do que em apresentar também as características do gêneros e estratégias de ensino.

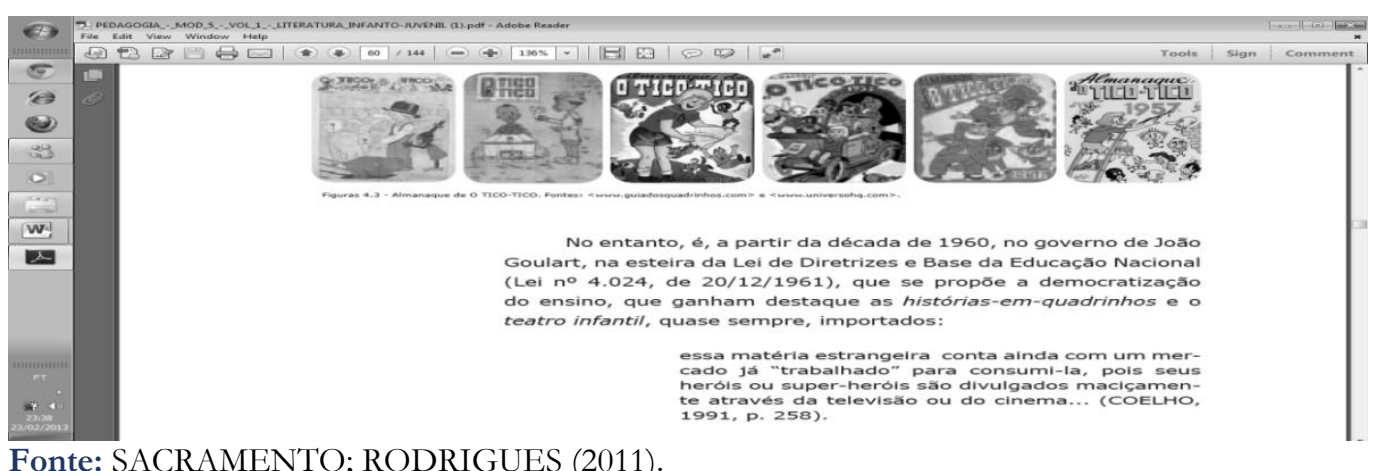

Fonte: SACRAMENTO; RODRIGUES (2011). 


\section{Dialogia}

FARIAS JR, Jorge França de. Gêneros textuais e livros didáticos: um estudo de caso na educação a distância $(\mathrm{EaD})$

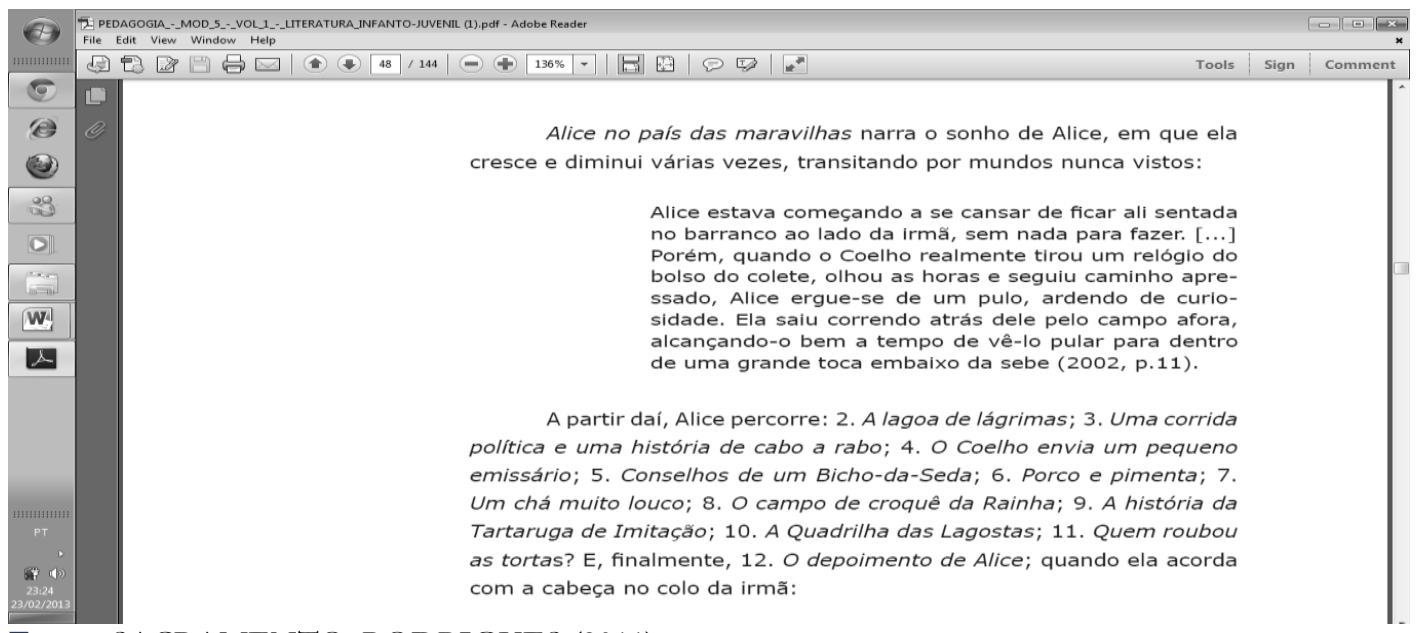

Fonte: SACRAMENTO; RODRIGUES (2011).

Com relação aos materiais de Letras, observou-se um aprofundamento teórico adequado, destacando-se o detalhamento dos aspectos constitutivos articulado com exemplos dos gêneros, como nas figuras abaixo.

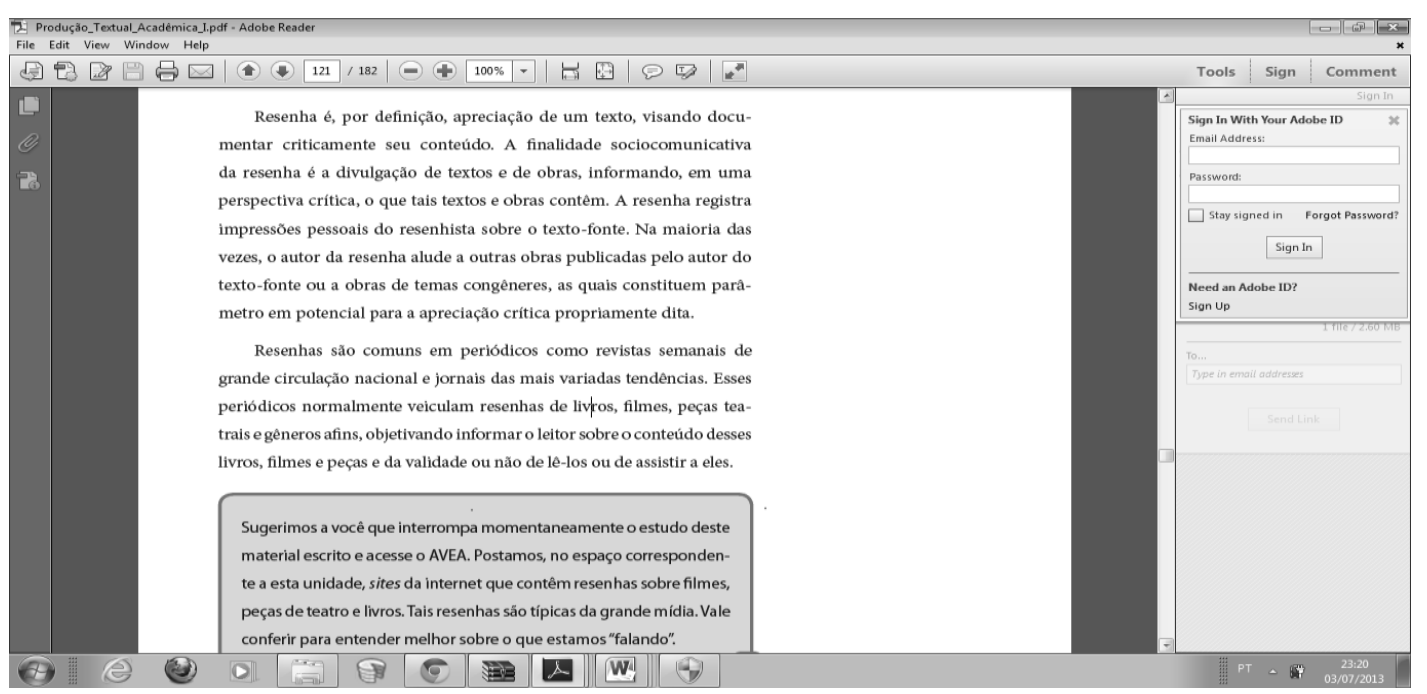

Fonte: GEHRKE (2009).

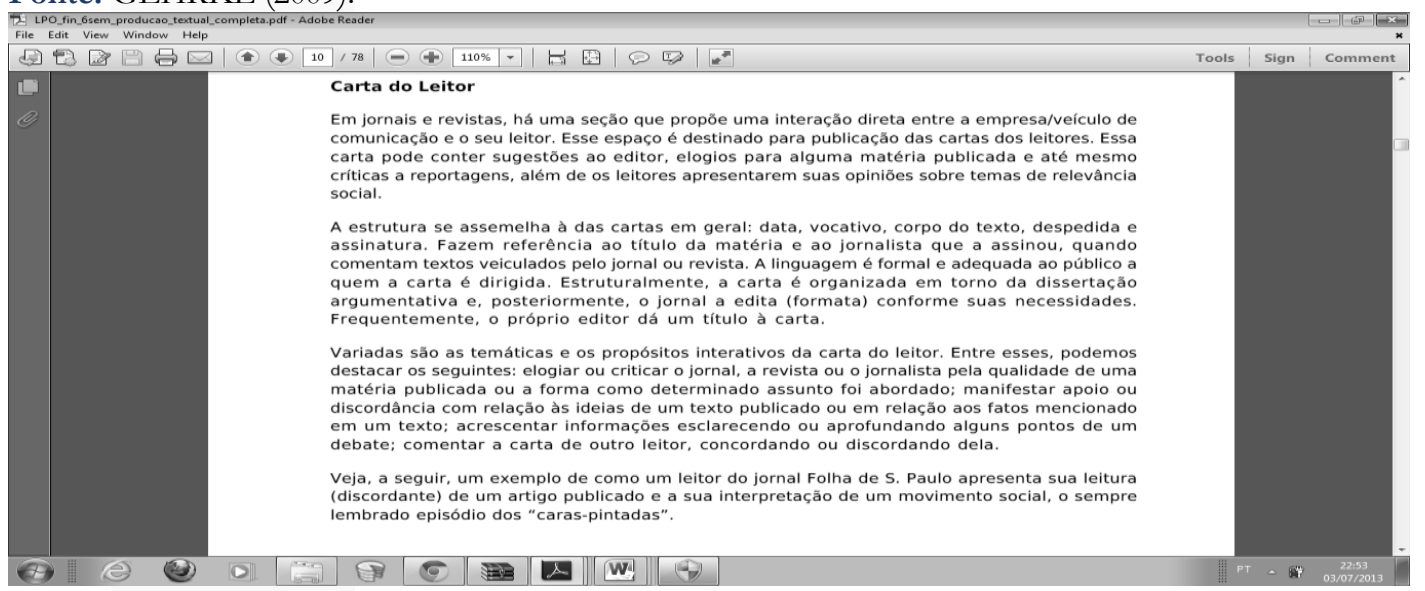

Fonte: GEHRKE (2009). 
FARIAS JR, Jorge França de. Gêneros textuais e livros didáticos: um estudo de caso na educação a distância (EaD)

Percebe-se, assim, que, quanto ao trabalho teórico dos gêneros nos livros de Pedagogia, ha uma abordagem pouco aprofundada, resultando em um material carente de explicação teórica básica para a formação do aluno de nível superior, ao contrário do que acontece com os materiais de Letras.

Quanto ao aspecto da iconicidade, Silva (2010), citando Fernandez (2010, p.400), explica:

O principal papel das ilustrações em materiais impressos para EAD é o de esclarecer e explicar um conceito ou de fornecer uma necessária contextualização. Para tanto, elas precisam estar em estreita unidade com o texto que complementam, sob pena de introduzir elementos distratores em relação ao conteúdo que está sendo tratado.

Percebeu-se nos materiais de ambos os cursos o emprego razoável desse aspecto. São inseridos outros gêneros que auxiliam no entendimento do conteúdo, normalmente em formato de boxe ou ao final de cada capítulo (biografia, nota/verbete). Destaca-se que também orientam os alunos quanto à utilização desse recurso desde as páginas iniciais dos materiais, como se pode observar na passagem seguinte.

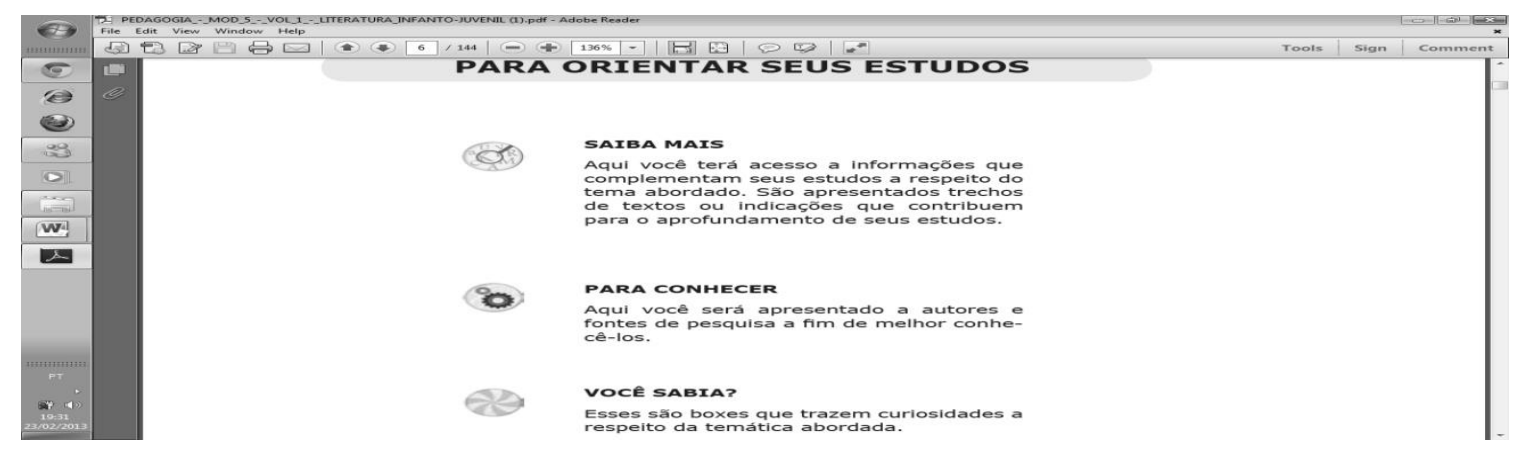

Fonte: SACRAMENTO; RODRIGUES (2011).

\subsection{Atividades propostas}

Segundo Silva (2010, p. 332), nos materiais didáticos impressos para EaD: “(...) éfundamental que o professor/autor crie situações diversificadas de aprendizagem, por meio de atividades que contemplem os variados estilos de aprendizagem dos alunos/leitores”. Sendo assim, com relação à abordagem dos gêneros textuais empregados, deve-se atentar para que as atividades possibilitem a aplicação dos conhecimentos teóricos adquiridos de maneira articulada à prática social, e não à simples inserção do gênero.

A seguir, elencam-se os principais tipos de atividades empregadas em materiais didáticos para $\mathrm{EaD}$, os quais foram utilizados na avaliação dos livros selecionados: 1) de pesquisa (busca de conteúdos em fontes variadas e sistematização dados coletados); 2) de sintese (comparação de ideias ou concepções diferentes sobre um mesmo tema, opiniões sobre alguma teoria, sistematização de conclusões sobre as leituras); 3) práticas (articulação de conhecimentos propostos à realidade e 
experiências de mundo); 4) de interação (realizadas nos ambientes virtuais de aprendizagem (AVA), na plataforma virtual do curso (fórum, chat, correio eletrônico, listas, glossários interativos, etc.) ou direcionadas para o ciberespaço (blogs, comunidades virtuais, redes sociais, youtube, etc.); 5) de avaliação (construção de diários, memoriais reflexivos, portfólios de aprendizagem, resolução de quir. que promovem a autoavaliação.); e 6) colaborativas (formação de grupos, organização de júri simulado, criação de gincanas virtuais, campeonatos virtuais, produção textual coletiva por meio de wikis, etc.) (SILVA, 2010, p. 332-334).

Nos materiais analisados, percebeu-se uma disparidade na qualidade de tais exercícios em relação aos dois cursos, o que reflete na concepção de formação educacional de cada uma das áreas.

De modo geral, os dois livros de Pedagogia propõem atividades de interpretação bastante superficiais, que se limitam ao óbvio - como a questão a) dos exemplos abaixo - ou questões do tipo "vale-tudo", conforme Marcuschi (2008), que admitem qualquer resposta, não havendo possibilidade de o aluno/leitor se equivocar - como em b). Isso reflete por parte dos autores a noção de compreensão como uma atividade de simples e natural decodificação de um conteúdo objetivamente inscrito no texto, conforme explanado em Marcuschi (2008).

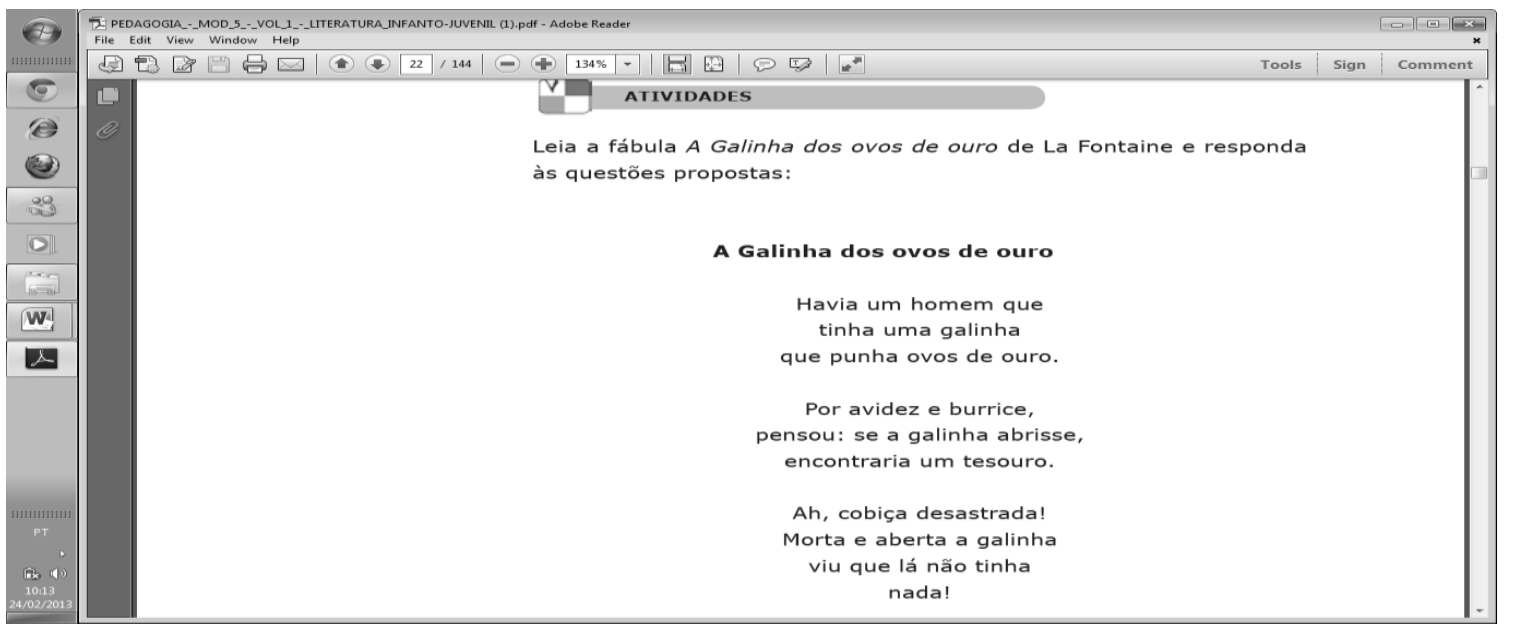

Fonte: SACRAMENTO; RODRIGUES (2011). 


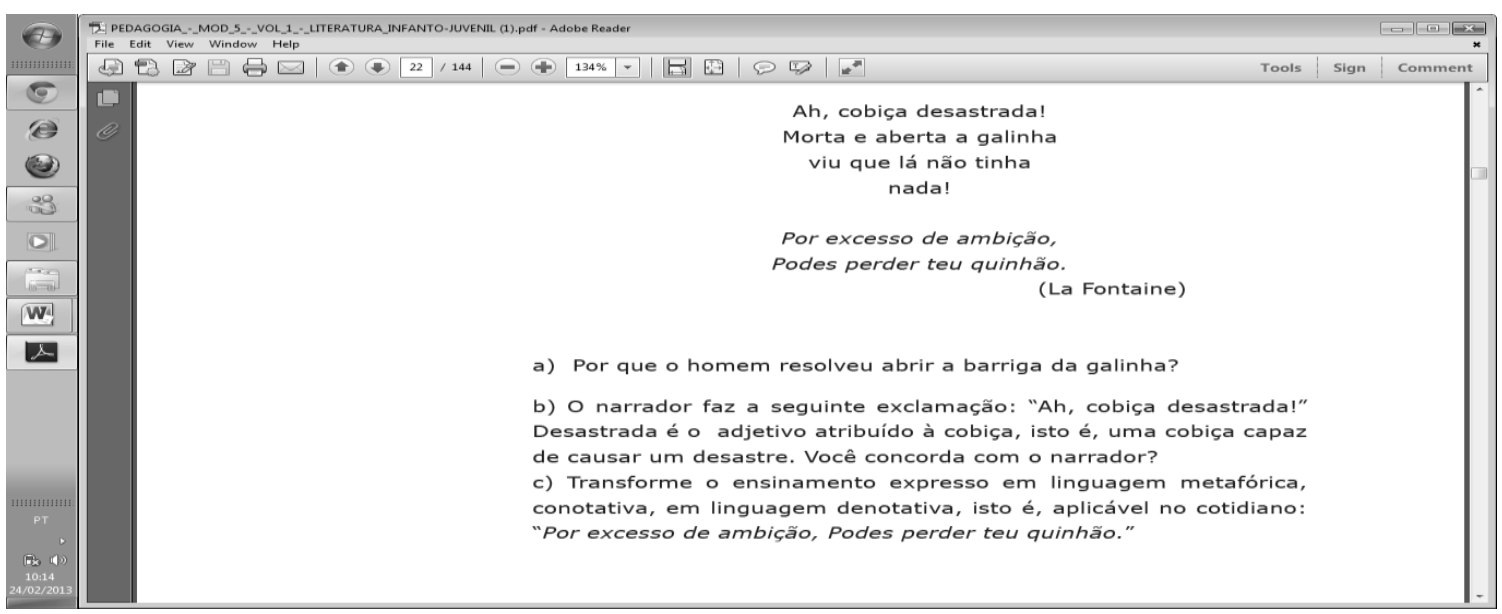

Fonte: SACRAMENTO; RODRIGUES (2011).

É importante ressaltar que a análise dessas questões interpretativas está fundamentada em Marcuschi (2008), em que o autor reúne as tipologias de perguntas de compreensão em livros didáticos de língua portuguesa típicas dos anos 1980-1990. Percebe-se, no quadro produzido pelo linguista, que ele se refere a questões voltadas para os níveis fundamental e médio. No entanto, percebemos que nos livros de Pedagogia analisados, voltados para nível superior e publicados nos anos 2000, ainda persistem tais abordagens incoerentes, o que reflete também desatenção às pesquisas teóricas.

Em muitos casos, resta dúvida se as questões foram destinadas ao aluno/leitor do curso de Pedagogia ou se são sugestões de atividades para o graduando da EaD utilizar em prática de sala de aula, o que interfere também na clareza do material didático, aspecto fundamental que age como atenuante da distância física entre professor e aluno, conforme Preti (2010).

Nos dois livros de Pedagogia são também empregadas comumente, conforme as tipologias elencadas por Silva (2010, p. 332), citadas acima, questões dos tipos pesquisa, prática e colaborativa. A princípio, seriam aspectos positivos no material, porém percebem-se algumas inadequações. Embora as questões apelem para o aproveitamento posterior da atividade proposta, quando o graduando estiver em prática de sala de aula, não é exigido do aluno nenhuma reflexão crítica sobre a prática, como se pode observar na passagem a seguir. 


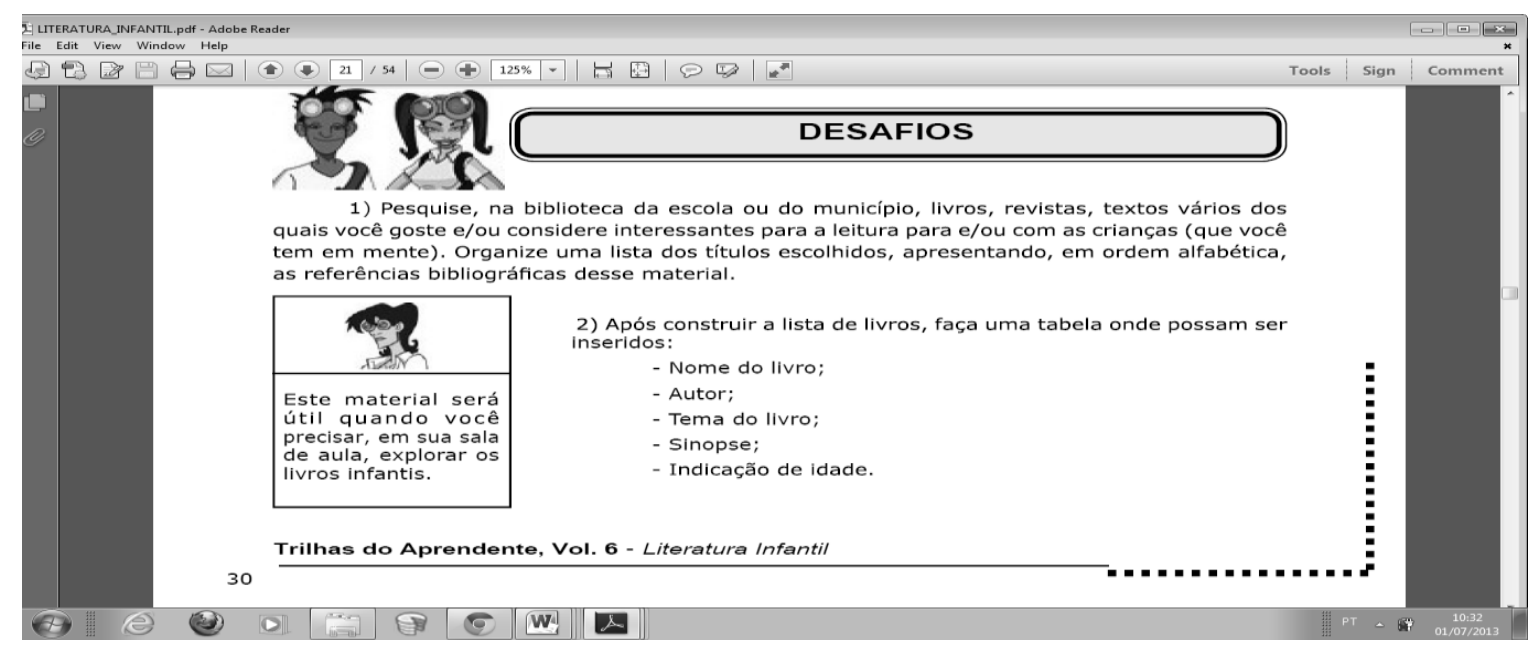

Fonte: SILVEIRA; In: BRENNAND. (2008).

Já entre os livros de Letras, percebe-se que as questões exploram muito mais a prática em favor da formação do próprio graduando, ou seja, há uma exigência maior quanto ao aproveitamento teórico em situações práticas. Observa-se, nesses materiais, o emprego variado das tipologias de atividades, sendo mais recorrentes as dos tipos prática, de interação e de pesquisa, como no exemplo seguinte.

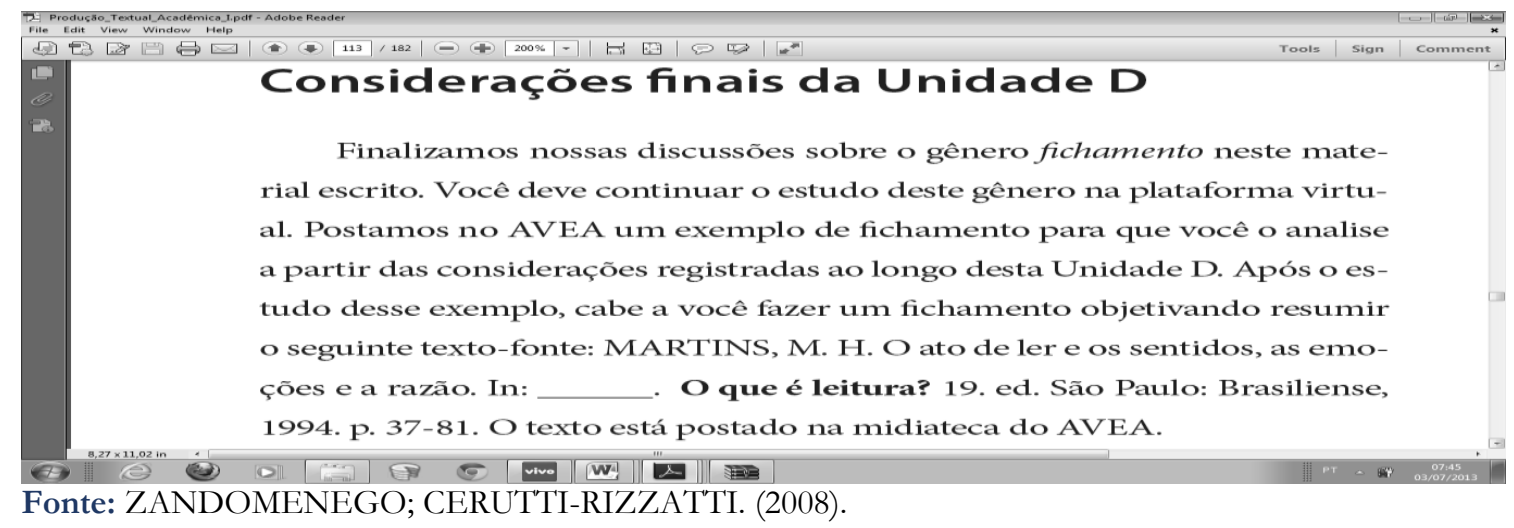

Também destaca-se a adequação dos dois livros de Letras quanto ao dialogismo e às relações intratextuais necessários ao material didático para EaD. Conforme Silva (2010, p.238), (...) o autor deve sugerir que os leitores avancem ou retrocedam na leitura, a fim de rever conteúdos propostos anteriormente ou antecipar propostas de atividades ou informações que serão apresentadas.

Esses aspectos ficam claros no exemplo a seguir, em que o professor/autor explica todo o processo de realização da atividade proposta, estabelecendo uma postura de orientação bastante esclarecedora e parecida com a modalidade presencial. 


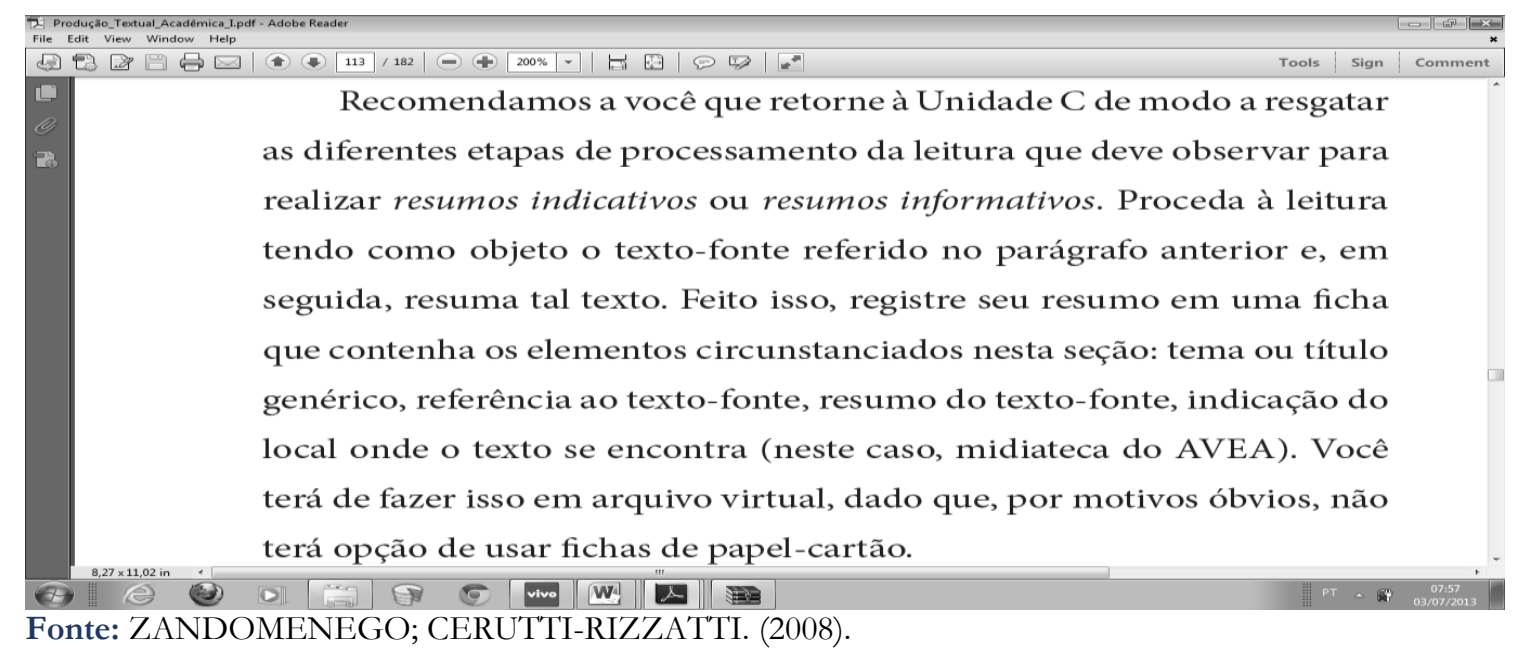

Nota-se, portanto, uma diferença de qualidade entre os materiais didáticos dos dois cursos, também, com relação à abordagem dos gêneros textuais nas atividades propostas.

\subsection{Produção textual acadêmica}

Com relação à produção textual de gêneros acadêmicos, vejamos que em nenhum dos dois livros de Pedagogia é exigido do aluno atividades, leituras ou mesmo são feitas reflexões que o despertem para a produção e divulgação de textos acadêmicos. Já nos livros de Letras, apenas um deles — Produção Textual Acadêmica I — o faz, e de maneira satisfatória, incentivando tal prática desde o início da disciplina, e não apenas na proposição de atividades, como na passagem a seguir:

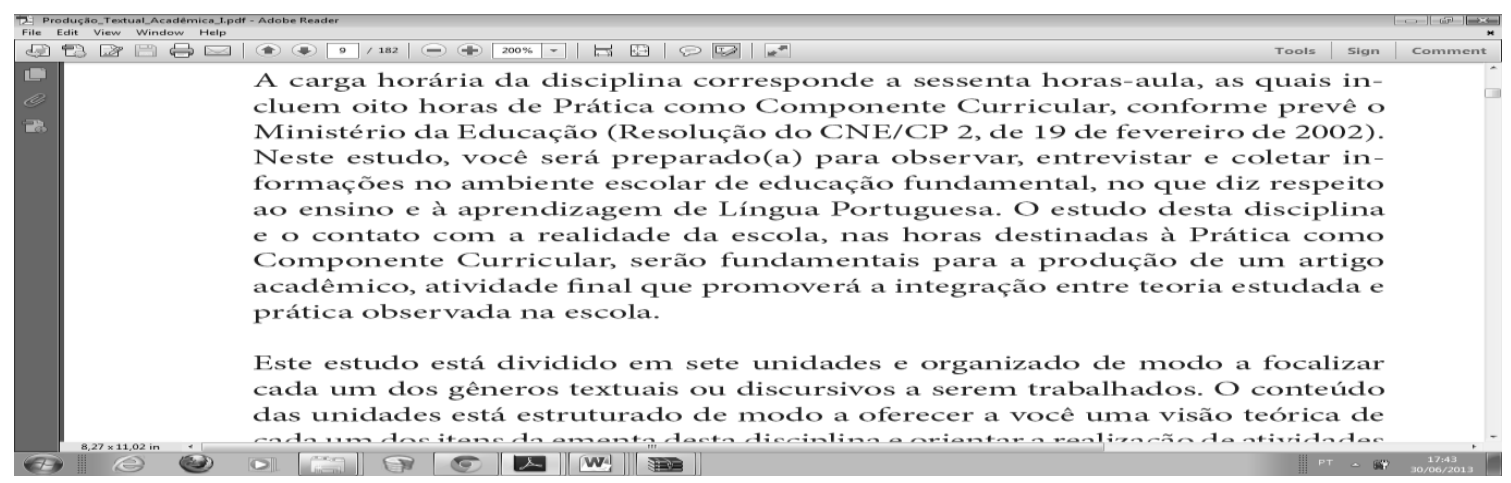

Fonte: ZANDOMENEGO; CERUTTI-RIZZATTI. (2008).

Segundo Silva (2011, p. 324),

$\mathrm{Na}$ EaD, é essencial o papel do professor como mediador, incentivador, motivador, no sentido de produzir um número cada vez maior de representações (presentificações) que estimulem os alunos à reflexão. Nesse processo de presentificação, o professor pode se revelar presente por meio da escrita dialogada na produção de materiais didáticos, priorizando um estilo conversacional e dialógico.

Nesse sentido, ainda que não seja objetivo específico dos demais livros trabalhar exclusivamente os gêneros acadêmicos, como ocorre com o Produção Textual Acadêmica I, esse 
incentivo deveria ser feito por parte dos autores, uma vez que na modalidade presencial, independentemente da disciplina ofertada, a importância da divulgação científica é bastante enfatizada pelos professores.

Características essencial na construção dos materiais didáticos impressos para EaD, a intertextualidade pode ser explorada de diversas maneiras. Segundo Silva (2010, p. 327), citando Freire [(1975); 2002]:

\begin{abstract}
Além do dialogismo no processo de interação verbal, os materiais didáticos podem explorar o diálogo entre textos (intertextualidade), propiciando uma abordagem ancorada na memória intertextual dos aprendizes. Também as conexões dialógicas entre os materiais didáticos impressos e as dimensões socioculturais, por meio do amplo diálogo entre linguagem e mundo, certamente poderão estimular os alunos/leitores à problematização e à leitura crítica do mundo, com vistas à criticidade e à autonomia.
\end{abstract}

Nos materiais analisados, notou-se, de maneira geral, que os autores utilizam essa estratégia tanto considerando-a como um conteúdo didático importante a ser tratado na construção dos gêneros, quanto manifestando-a no livro considerado como um macrogênero.

Tais ocorrências podem ser observadas nos exemplos a seguir, em que os autores trazem a explicação metalinguística sobre a intertextualidade, fazendo uso desse próprio recurso e, em seguida, apontam a importância da utilização desse aspecto textual para a construção dos gêneros abordados.

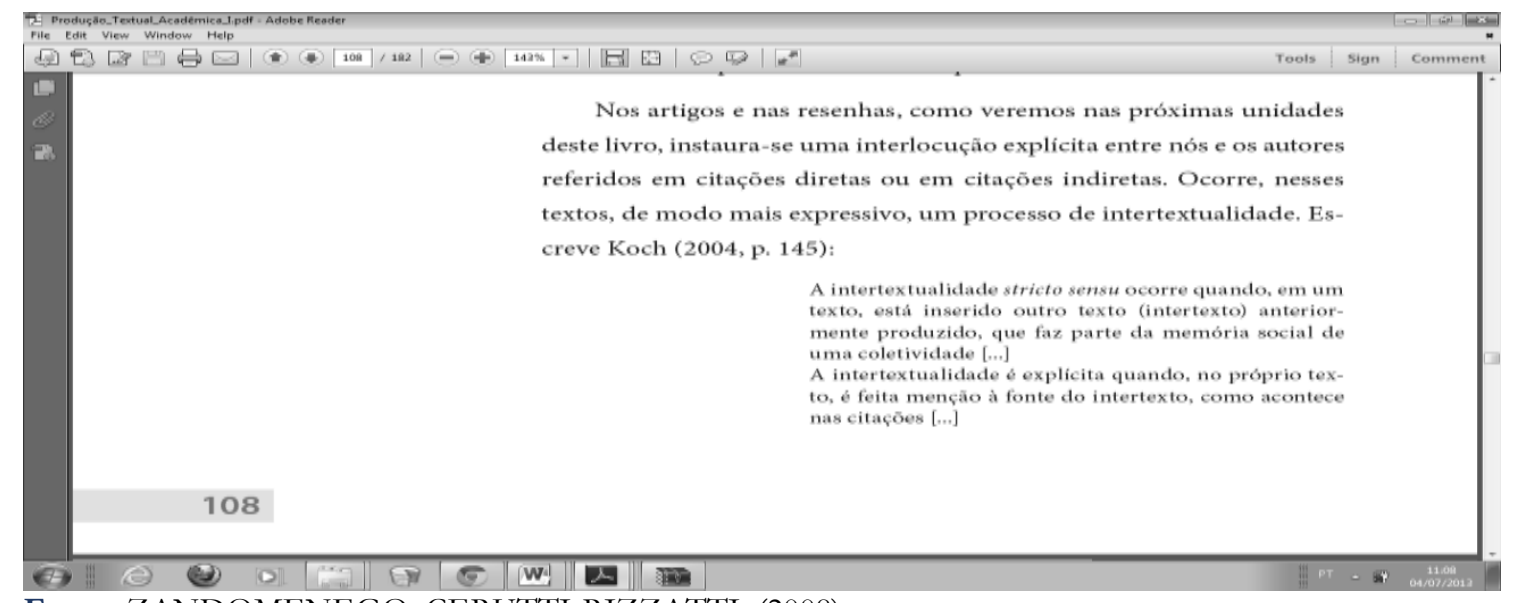

Fonte: ZANDOMENEGO; CERUTTI-RIZZATTI. (2008). 


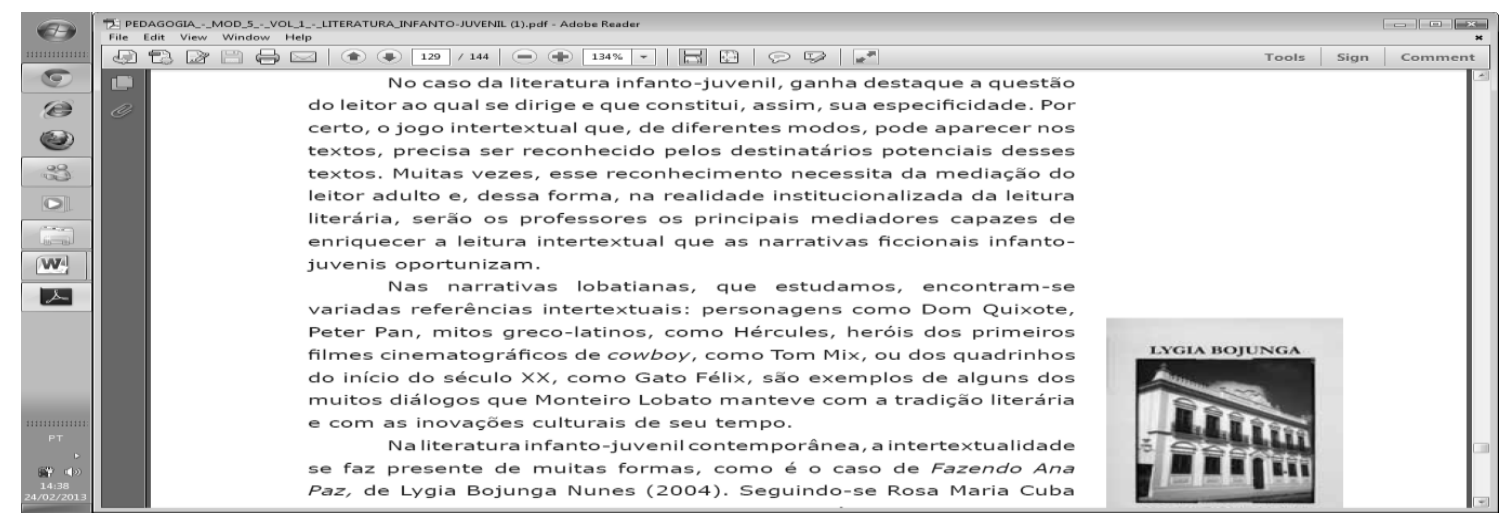

Fonte: SACRAMENTO; RODRIGUES. (2011).

Por fim, quanto à utilização de gêneros multimodais e ao aspecto da intergenericidade, notou-se plena ausência de qualquer explicação metalinguística ou até mesmo inserção de exemplares desses gêneros nos materiais de ambos os cursos.

Acredita-se que os autores poderiam ter trabalhado tal aspecto, por exemplo, ao discutir sobre literatura infanto-juvenil e reprodutibilidade técnica, em que inserem o gênero história em quadrinhos sem fazer qualquer reflexão sobre a característica multimodal de tal gênero.

\section{Considerações finais}

Os materiais didáticos impressos para $\mathrm{EaD}$, em função da própria modalidade de aprendizagem, requerem uma atenção especial a fim de que constituam objetos de ensino eficazes. Os aspectos constitutivos desses instrumentos pedagógicos estão cada vez mais sendo discutidos e, nesta pesquisa, percebeu-se a complexidade que há em sua elaboração.

A importância de se analisar a abordagem de gêneros textuais não só é fundamental para que se constatem as características do uso dos gêneros em tais materiais, mas, principalmente, para que se possa auxiliar nas adequações necessárias à sua produção.

Conforme análise realizada, fazendo-se um cotejo entre as abordagens de gêneros textuais presentes nos livros de ambos os cursos, percebeu-se que, embora os livros de Pedagogia se voltem para reflexões acerca da literatura infantil e infanto-juvenil, não sendo seu objetivo o trabalho específico com gêneros textuais - como ocorre com os livros de Letras -, fica claro que esses materiais requerem um pouco mais de atenção no trabalho teórico e na articulação prática dos gêneros neles inseridos.

Vale enfatizar, entretanto, que a diferença de qualidade entre os materiais didáticos dos cursos de Pedagogia e Letras exacerbam a importância em diferentes níveis por cada curso. Nos materiais de Letras, busca-se muito mais aplicação, pesquisa e reflexão teórica sobre os gêneros 
trabalhados por parte dos alunado, viabilizando ao graduando uma formação mais sólida quanto à aplicação do conhecimento científico. Já os livros didáticos de Pedagogia trabalham muito mais questões de interpretação que não exigem a reflexão sobre os gêneros atrelados ao conteúdo ou apelam para a produção de material para a prática docente, por parte do alunado.

Por fim, com relação à produção textual de gêneros acadêmicos, observou-se que em nenhum dos dois livros de Pedagogia há exigência de que o aluno produza atividades, leituras ou mesmo são feitas reflexões que o despertem para a produção e divulgação de textos acadêmicos. Por sua vez, nos livros de Letras, em apenas um deles (Produção Textual Acadêmica I) houve esta ocorrência de modo satisfatório, com incentivo de tal prática desde o início da disciplina, e não apenas na proposição de atividades.

\footnotetext{
${ }^{1}$ Este artigo é fruto de uma pesquisa de Iniciação Científica, orientada por mim, co-orientada pela Profa. Ivanda M. M. Silva e apoiada pela UFRPE. Agradeço à minha ex-orientanda, Izabela Pereira de Fraga, por sua dedicação à pesquisa e à citada professora e colega, por sua colaboração com um tema que lhe é bastante caro.
}

\section{Referências}

BAKHTIN, M. Gêneros do discurso. In: Estética da Criação Verbal. São Paulo: Martins Fontes, 1997.

BRASIL, Secretaria de Educação Fundamental. Parâmetros Curriculares Nacionais: terceiro e quarto ciclos do ensino fundamental: língua portuguesa. Brasília: MEC/SEF, 1998.

DIONÍSIO, A. P. Gêneros multimodais e multiletramento. In: KARWOSKI, A. M; GAYDECZKA, B; BRITO, K. S. (orgs.). Gêneros textuais: Reflexões e ensino. Rio de Janeiro: Ed. Lucerna, 2005, p. 159177.

GEHRKE, N. A. . EAD 1108 - Produção Textual. (Desenvolvimento de material didático ou instrucional Disciplina EAD), 2009.

GEHRKE, N. A. EAD 1108 - Produção Textual. (Desenvolvimento de material didático on instrucional.Disciplina EAD), 2009. p. 121.

JEWITT, C.\& KRESS. G. Multimodal literacy: new literacies and digital epistemologies, v. 4, Oxford, Peter Lang, 2003.

KRESS, G. \& VAN LEEUWEN, T. Reading Images: the grammar of visual design. New York, Routledge, 1996.

KRESS, G. Explanation in Visual Communication. London: University of London, 1993.

KRESS, G. Multimodal discourse: the models and media of contemporarycommunication. New York, Oxford University Press, 2001. 
MACHADO, A. \& BEZERRA, M. Produção textual, análise de gêneros e compreensão. São Paulo: Parábola, 2008.

MARCUSCHI, L. A. Gêneros textuais: definição e funcionalidade. In: DIONÍSIO, A.; MACHADO, A. \& BEZERRA, M. Gêneros textuais e ensino. Rio de Janeiro: Lucerna, 2002.

PRETI, D. Produção de Material Didático Impresso: Orientações Técnicas e Pedagógicas. Cuiabá: $\mathrm{UAB} / \mathrm{UFMT}, 2010$.

SACRAMENTO, S. M. P. \& RODRIGUES, I. O. Pedagogia - Literatura Infanto-juvenil, Módulo 5, Volume 1, EAD. Ilhéus: Edictus, 2011.

SACRAMENTO, S. M. P. do; RODRIGUES, I. de O. Pedagogia - Literatura Infanto-juvenil. Módulo 5, Volume 1, EAD. Ilhéus: Edictus, 2011, p. 60.

SILVA, I. M. M. Elaboração de materiais didáticos impressos para Educação a Distância. In: Eutomia Revista Online de Literatura e Linguística. Ano IV, Volume 1, Julho 2010. Disponível em http://www.revistaeutomia.com.br/eutomia- ano4-volume1- linguistica.html. Acesso em dezembro de 2012.

SILVEIRA, M. C. A. de A. Literatura Infantil. In: BRENNAND,Edna Gusmão de Góes; ROSSI, Silvio José; BEZERRA, Lebiam Tamar Silva. Trilhas do Aprendente. João Pessoa: Editora Universitária da UFPB, 2008. V. 6. p.19- 46.

SILVEIRA, M. C., A. de A. Literatura Infantil. In: BRENNAND, Edna Gusmão de Góes; ROSSI, Silvio José; BEZERRA, Lebiam Tamar Silva. Trilhas do Aprendente. João Pessoa: Editora Universitária da UFPB, 2008. p. 21

ZANDOMEnEgO, D. CERUTTI-RIZZATTI, M. E. Produção Textual Acadêmica I $1^{\circ}$ período. Florianópolis: LLV/CCE/UFSC, 2008. p. 113. 
Anexo

\begin{tabular}{|c|c|c|}
\hline \multicolumn{3}{|c|}{ ROTEIRO PARA A ANÁLISE DE GÊNEROS TEXTUAIS EM LIVROS DIDÁTICOS PARA EAD } \\
\hline \multicolumn{3}{|l|}{ Instituição } \\
\hline \multicolumn{3}{|l|}{ Curso } \\
\hline Disciplina & $\mathrm{N}^{\mathrm{o}}$ de páginas & \\
\hline \multicolumn{3}{|l|}{ Autor(a) } \\
\hline Avaliadora & Data & \\
\hline \multicolumn{3}{|l|}{ Referência } \\
\hline Categorias de análise & Considerações & $\begin{array}{c}\text { Exemplos de } \\
\text { passagens }\end{array}$ \\
\hline $\begin{array}{l}\text { O livro didático analisado } \\
\text { apresenta diversidade de } \\
\text { gêneros textuais? }\end{array}$ & $\begin{array}{l}\text { ( ) Sim, o material apresenta diversidade de gêneros } \\
\text { textuais pertencentes aos variados domínios } \\
\text { discursivos. } \\
\text { ( ) Sim, mas o material restringe-se a determinado } \\
\text { domínio discursivo (literário, jornalísticos etc.) } \\
\text { ( ) Não, o material não apresenta a diversidade de } \\
\text { gêneros textuais. }\end{array}$ & \\
\hline $\begin{array}{l}\text { De que forma a diversidade de } \\
\text { gêneros é apresentada? }\end{array}$ & $\begin{array}{l}\text { ( ) O material apresenta a diversidade de gêneros } \\
\text { textuais de modo adequado, com vários exemplos } \\
\text { propostos para leitura e produção textual. } \\
\text { ( ) O material não apresenta a diversidade de gêneros } \\
\text { textuais de modo adequado, pois xxxxxx }\end{array}$ & \\
\hline $\begin{array}{l}\text { Os gêneros abordados } \\
\text { vinculam-se à proposta } \\
\text { curricular destinada? }\end{array}$ & $\begin{array}{l}\text { ( ) Sim, a temática dos gêneros utilizados relacionam- } \\
\text { se com os componentes curriculares a que se propõem. } \\
\text { ( ) Não, os gêneros utilizados apresentam-se de forma } \\
\text { aleatória ou apenas ilustrativa ao assunto tratado pela } \\
\text { disciplina. }\end{array}$ & \\
\hline
\end{tabular}

Recebido em: 23 ago. 2020/ Aprovado em: 25 nov. 2020

Cite como

(ABNT NBR 6023:2018)

FARIAS JR, Jorge França de. Gêneros textuais e livros didáticos: um estudo de caso na educação a distância (EaD). Dialogia, São Paulo, n. 36, p. 532-549 set./dez. 2020. Disponível em: https://doi.org/10.5585/dialogia.n36.17970.

American Psychological Association (APA)

Farias, J. F., Jr. (2020, set./dez.). Gêneros textuais e livros didáticos: um estudo de caso na educação a distância (EaD). Dialogia, São Paulo, 36, p. 532-549. https://doi.org/10.5585/dialogia.n36.17970. 